\title{
IN VITRO SHEAR BOND STRENGTH STUDY OF NEW AND RECONDITIONED STAINLESS STEEL ORTHODONTIC BRACKETS
}

\author{
Hanan A. Ismail ${ }^{1}$, Hassan A. Moussa ${ }^{2}$, \\ Moustafa N. Aboshelib ${ }^{3}$, Mazen S. Al-Ammari ${ }^{4}$
}

ABSTRACT:

This study was conducted to compare the shear bond strength between new and reconditioned brackets using four reconditioning techniques on two bracket base designs. Eighty specimens were divided into two equal groups according to bracket base designs, mesh-6ase brackets group (Ormco), and laser-6ase brackets group (Dentaurum). In each group, new brackets were bonded to premolar teeth and the bond strength was recorded as a base line (control 1). Each group was further subdivided into five equal subgroups as follows: first subgroup, debonded brackets were removed, new brackets were bonded and the bond strength was recorded as (control 2), for the remaining four subgroups, debonded brackets were rebonded after reconditioning by $30 \mu \mathrm{m}$ silanated sand6lasting, $50 \mu \mathrm{m}$ non silanated sandblasting, acid bath, and carbide bur and their bond strengths measured. Statistical analysis revealed that there was significant difference in the bond strength between the two bracket base designs used $(\mathcal{P}=0.000)$ as laser-structured base brackets demonstrated higher

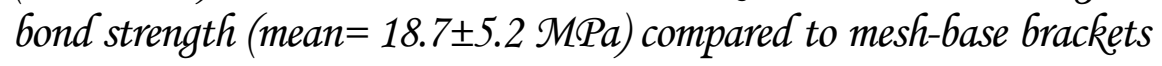

1- Professor of Orthodontics, Faculty of Dentistry, Alexandria University.

2- Lecturer at the Orthodontic Department, Faculty of Dentistry, Alexandria University.

3- Lecturer at the Dental Biomaterials Department, Faculty of Dentistry, Alexandria University.

4- Post Graduate Student, Orthodontic department, Alexandria University. 
Egyptian

Orthodontic Journal

(mean $=14.6 \pm 4.2 \mathcal{M P a})$. Moreover, there was significant difference $(\mathcal{P}=0.000)$ in bond strength between the different reconditioning techniques. On the contrary, there was no significant difference $(\mathcal{P}=0.840)$ on the interaction between the type of bracket base design and reconditioning technique as 6oth designs of bracket base responded similarly to each reconditioning technique. In conclusion, bracket reconditioning using sandblasting technique was efficient and technically simple, and might provide cost reduction for orthodontists and patients alike.

\section{INTRODUCTION}

In orthodontics, as well as in other dental fields, there is a trend to simplify the technical procedures to reduce operative time and treatment costs. Orthodontic bracket bonding must be strong enough to withstand stresses and shearing forces. Despite the material advancements of bonding and the increase in efficiency of treatment, a commonly encountered problem during the course of treatment that continues to be a challenge in clinical practice is a bracket bond failure which is usually the results of either the patient accidentally applying inappropriate forces to the bracket, poor bonding technique, or bracket base design. ${ }^{(1)}$

Bond failure of brackets not only can be frustrating for the practitioner, but also can significantly affect treatment efficiency and has an economic impact on a practice. ${ }^{(2)}$ Bracket bond strength depends on several factors; bracket base retention mechanisms one of the factors that influences the shear bond strength of metal brackets. Mesh pad is the system most commonly used for retention. ${ }^{(3-6)}$

However, orthodontists are commonly faced with the decision of what to do with loose brackets, and or with inaccurately located brackets that need repositioning during treatment. One solution is to recondition the brackets. The reconditioning process basically consists of removing the bonding agent remnants from the bracket base, thus allowing the bracket to be reused without causing damage to the retention mesh while preserving its retentive characteristics. $^{(7)}$ A rapid office method of treating debonded brackets to produce clinically acceptable bond strengths with minimal changes in the 
physical properties of the brackets would benefit the profession economically. ${ }^{(8)}$ The effect of reconditioning depends on the type of reconditioning process used, the type of steel from which the bracket is constructed, whether the bracket is milled or cast, and whether the bracket has a mesh pad or a non-mesh undercut integral pad. ${ }^{(9)}$

The purpose of this study was to compare the shear bond strength between new and reconditioned brackets using four reconditioning techniques on two bracket base designs.

The proposed null hypothesis was: no difference in SBS between mesh-based and laser-structured based brackets. There was a difference in SBS between new and reconditioned brackets but there was no difference in SBS between the reconditioning techniques using sandblasting, carbide bur, and acid bath.

\section{MATERIALS AND METHODS}

A total of eighty premolar teeth extracted for orthodontic purposes were collected for the purpose of this study. The teeth were washed, cleaned and stored in normal saline solution at room temperature to prevent dehydration until the time of mounting. Metal ring was used to make self cure acrylic blocks for holding the extracted premolars during testing procedures. Straight wire metal brackets with two different base designs for bonding on premolar teeth were tested. Table (I).

Eighty samples were divided equally into two main groups according to the bracket base designs: 40 samples: Mesh-base brackets group,40samples: Laser-structured base brackets group. In each group, new brackets were bonded and the bond strength was recorded as a base line (control 1). Each group was further subdivided into five subgroups as follows; the first subgroup: For calibration of the rebonding procedures, and the other four subgroups: For reconditioning techniques.

\section{Calibration of the rebonding procedures (Sixteen samples)}

Eight samples from each main group were used to investigate the effect of rebonding procedures on shear bond strength. Teeth from each main group were rebonded with new brackets. Rebond shear bond 
strength values were recorded as (control 2) to make sure that the rebonding surface treatment performed in the study produced reliable bond strength values compared to the control groups (control 1) and that the surface of enamel was not irreversibly damaged during the first debonding procedures.

Reconditioning subgroups (Sixty four samples)

Thirty two samples from each main group were further subdivided into four subgroups of eight teeth each according to the type of bracket reconditioning technique performed, Table (II). The same teeth were rebonded with their corresponding reconditioned brackets, and the rebond shear bond strength values were recorded.

Table (I): Types of bracket base designs tested.

\begin{tabular}{|l|l|c|c|c|}
\hline Bracket Name & No. & Manufacturer & Base Design & $\begin{array}{c}\text { Surface } \\
\mathbf{a r e a}\left(\mathbf{m m}^{\mathbf{2}}\right)\end{array}$ \\
\hline Mini $2000^{*}$ & 40 & Ormco & Mesh-base & 9.63 \\
\hline Discovery** $^{* *}$ & 40 & Dentaurum & Laser-structured base & 12.93 \\
\hline
\end{tabular}

Table (II): Reconditioning subgroups

\begin{tabular}{||l|c|c|c|c|c|c|c|c||}
\hline New Brackets & \multicolumn{3}{|c|}{$\begin{array}{c}\text { Mesh-based brackets } \\
\text { group (32) }\end{array}$} & \multicolumn{3}{c||}{ Laser-structured based brackets } \\
& \multicolumn{3}{|c||}{ group (32) } \\
\hline & $(8)$ & $(8)$ & $(8)$ & $(8)$ & $(8)$ & $(8)$ & $(8)$ & $(8)$ \\
& $30 \mu \mathrm{m}$ & $50 \mu \mathrm{m}$ & Acid & Carbide & $30 \mu \mathrm{m}$ & $50 \mu \mathrm{m}$ & Acid & Carbide \\
& Silanated & Non-silanated & bath & bur & Silanated & Non-silanated & bath & bur \\
& aluminum & aluminum & & & aluminum & aluminum \\
oxide & & & \\
oxide & & \\
Reconditioned & oxide & oxide & & & sandblasting & & \\
Brackets & sandblasting & sandblasting & & & sandblasting & & \\
& particle & particle & & & particle & particle & & \\
\hline
\end{tabular}

The buccal surface of each tooth was polished with a pumice paste using a rubber cup on a low-speed hand piece for 10 seconds. The enamel

*Ormco, California, USA

** Dentaurum, Ispringen, Germany.

Volume 43 - June 2013 
surface was then thoroughly rinsed and dried with an air spray for 30 seconds. $37 \%$ phosphoric acid etchant was applied to the enamel surface for 30 seconds using disposable microbrushes, followed by rinsing for 20 seconds using air-water spray, and drying with air spray for 20 seconds. The enamel bond was then applied in a thin coat to etched enamel using disposable microbrushes. Composite was applied to each bracket base, then, all brackets were bonded approximately in the center of the buccal surface of the teeth with $250 \mathrm{~g}$ force for 5 seconds to ensure uniform adhesive thickness. ${ }^{(10)}$ The excess composite was removed with a dental probe. The adhesive bracket tooth interface was exposed to the curing light for 20 seconds at a distance of $5 \mathrm{~mm}$ around the four edges of the brackets. The bonded teeth were stored in normal saline for 24 hours before testing. All brackets were bonded with the same light-cured bonding system ${ }^{*}$ and the same technique.

Each specimen was fixed on a holding ring positioned in the lower table of the universal testing machine ${ }^{* *}$. A chisel was secured to the upper table applied perpendicularly between the bracket base and tooth. The testing machine was turned on at a crosshead speed of $0.5 \mathrm{~mm}$ per minute, to shear the bracket off the tooth surface. The force required to debond each bracket was recorded in Kilograms on a monitor attached to the machine, and converted to megapascals as ratio of kilograms to the bracket surface area $\left(\mathrm{mm}^{2}\right)$.

After bond fracture (failure), brackets and enamel surfaces in each group were examined under magnification with stereomicroscope for the amount of adhesive remaining on the bracket base and the site of bond fracture (failure) using ARI score according to the index developed by Artun and Bergland. ${ }^{(1)}$

Score $(0)=$ All adhesive is left on the bracket base.

Score $(1)=$ More than $50 \%$ of the adhesive is left on the bracket base.

Score $(2)=$ Less than $50 \%$ of the adhesive is left on the bracket base.

Score (3) $=$ No adhesive is left on the bracket base.

* Ormco, California, USA.

** Comten industries, inc., Florida, USA. 
Egyptian

Orthodontic Journal

\section{Reconditioning procedures}

The residual composite resin on each tooth was carefully removed from the enamel with 12-fluted tungsten carbide bur in a low-speed hand piece at a speed of 25,000 revolutions per minute (rpm) under dry conditions. The removal of resin was considered complete when no resin was apparent on visual inspection. To prevent dehydration, all specimens were stored in a tightly sealed box lined by cotton soaked with normal saline until they were randomly assigned to the rebonding subgroups. Debonded brackets in each subgroup were reconditioned as the following:

\section{Sandblasting Subgroups}

The previously bonded brackets were reconditioned by sandblasting technique.Each bracket was held approximately $5 \mathrm{~mm}$ from the tip of a portable sandblasting unit (Micro Etcher II) ${ }^{*}$ and etched with $30 \mu \mathrm{m}$ silanated aluminum oxide particles or with $50 \mu \mathrm{m}$ non-silanated aluminum oxide particles until all visible bonding material was removed from the bracket base. Each bracket base was sandblasted for 20-40seconds (depending on the mount of residual bonding agent) under 5.5 bars $(80 \mathrm{psi}$ ) line pressure. The bracket was then rinsed and dried with compressed air.

\section{Acid bath Subgroups}

The previously bonded brackets were reconditioned by acid bath technique. The flame tip of a gas torch flame was pointed at the bracket base for a few seconds until the bonding agent started to ignite and burn. The bracket was then submerged for 3 minutes in a solution of $32 \%$ hydrochloric acid. Then, the bracket rinsed under running water for 30 to 60 seconds, air dried and ready for rebonding.

\section{Carbide bur Subgroups}

The previously bonded brackets were reconditioned using 12-fluted tungsten carbide burs operated on low-speed hand piece at a speed of 25,000 rpm for approximately 25 seconds until all residues had been removed.

*Danville, California, U.S.A.

Volume 43 - June 2013 
Egyptian

Orthodontic Journal

\section{Surface roughness of reconditioned brackets}

Specimens were ultrasonically cleaned and fixed on the measuring table. Bracket base surface was placed parallel to horizon. The surface roughness was measured using contact stylus which travelled $4 \mathrm{~mm}$ on the surface. Average surface roughness $R_{a}$ (average peak valley value) was measured 5 times on each specimen.

Scanning Electron Microscope (SEM) examination

After reconditioning of debonded brackets for each subgroup, they examined under magnification with scanning electron microscope, at operating magnification ranging from 200 to $1000 \mathrm{x}$ at $25 \mathrm{KV}$, to explore the effect of reconditioning techniques on bracket bases.

\section{Rebond shear bond strength testing (Rebonding procedures)}

The same teeth, after reconditioning, in each subgroup were rebonded with their corresponding reconditioned brackets, and the rebond shear bond strength values were evaluated and recorded using the same procedures in the initial bonding and initial shear bond strength testing.

\section{STATISTICAL ANALYSIS}

Data on the value of the shear bond strength of each group and subgroup was collected and tabulated. Descriptive statistics including the mean, standard deviation, minimum, and maximum were calculated, and the data was statistically analyzed by one-way and two-way analysis of variance (ANOVA) and Bonferroni post hoc tests $(\alpha=0.05)$.

\section{RESULTS}

Statistical analysis revealed that there was significant difference in the shear bond strength between the two bracket base designs used $(\mathrm{F}$ value $=29.357$ and $\mathrm{P}$ value $=0.000)$ as laser-structured base brackets demonstrated higher bond strength (mean $=18.7 \pm 5.2 \mathrm{MPa}$ ) compared to mesh-base brackets (mean $=14.6 \pm 4.2 \mathrm{MPa}$ ). Moreover, there was significant difference $(\mathrm{F}$ value $=17.967$ and $\mathrm{P}$ value $=0.000)$ in bond strength between the different reconditioning techniques. On the contrary, there was no significant difference $(\mathrm{F}$ value $=0.411$ and $\mathrm{P}$ value $=0.840)$ 
Egyptian

Orthodontic Journal

on the interaction between the type of bracket base design and reconditioning technique as both designs of bracket base responded similarly to each reconditioning technique (Table III). Descriptive statistics are summarized in (Table IV) and (Figs. 1 \& 2).

The results of the adhesive remnants were graded as per ARI ${ }^{(11)}$ and showed significant differences between the two different bracket base designs. Bond failure waslocated at the bracket-adhesive interface (ARI score of 3) with the mesh base brackets in $75 \%$ of the specimens indicating a greater trend for most of theadhesive to remain on the tooth with a distinct impression of the bracket mesh after debonding. Bond failure was located at the enamel-adhesive interface (ARI score of 0) with the laser-structured base brackets in $85 \%$ of the specimens. This indicated a greater trend for all adhesive toremain on the base after debonding (Fig. 3).

The results of the surface roughness measurements indicated that no correlation existed between bond strength and surface roughness (Table V). Examination of the bracket bases with scanning electron microscope revealed that the new brackets had smooth bases with clean retentive areas. Mesh-base showed multi-stranded wire structure, and the laser-structured base had small grains and rounded beads (Fig.4). Debonded both types of brackets, the retentive areas were filled with adhesive remnants (Fig.5). In $30 \mu \mathrm{m}$ silanated sandblasting subgroups the two types of bracket bases demonstrated dull and rough bases with clean retentive areas. The retentive areas were well-defined. Adhesive remnants were completely removed except in certain areas under the mesh-base (Fig.6). In $50 \mu \mathrm{m}$ non-silanated sandblasting subgroups, both bracket bases demonstrated also dull but morerough bases. The retentive areas were clean but less well-defined (Fig.7). In acid bath subgroups, incomplete removal of adhesives from both bracket bases was shown. The retentive areas were filled with adhesive, even though no adhesive was remaining on the bracket. Only the overhanging adhesive was found to have been removed (Fig.8). In carbide bur subgroups, also showed incomplete removal of adhesive from the bracket bases. The retentive areas and the adhesive were found scraped to the same level and the adhesive was removed to that level only. Flattening and loss of retentive areas was seen (Fig.9).

Volume 43 - June 2013 
Table (III): The statistical comparisons of the different groups and subgroups.

\begin{tabular}{|l|c|c|}
\hline \multicolumn{1}{|c|}{ Source } & F & $\boldsymbol{P}$ \\
\hline Groups & 29.357 & 0.000 \\
\hline Subgroups & 17.967 & 0.000 \\
\hline Groups * Subgroups & 0.411 & 0.840 \\
\hline
\end{tabular}

Table (IV): The descriptive statistics of the different groups and subgroups.

\begin{tabular}{||l|l|c|c|}
\hline Bracket base & Groups and Subgroups & Mean & Std. Dev. \\
\hline \multirow{4}{*}{$\begin{array}{l}\text { Mesh-Base } \\
\text { Brackets }\end{array}$} & Control 1: initial SBS & 14.6218 & 4.23530 \\
\cline { 2 - 4 } & Control 2: rebond new brackets & 15.3325 & 2.91228 \\
\cline { 2 - 4 } & $30 \mu \mathrm{m}$ silanated sandblasting & 14.1050 & 2.33531 \\
\cline { 2 - 4 } & $50 \mu \mathrm{m}$ non-silanated sandblasting & 11.6650 & 2.99456 \\
\cline { 2 - 4 } & Acid Bath & 8.3200 & 3.10881 \\
\cline { 2 - 4 } & Carbide Bur & 7.2550 & 4.00662 \\
\hline \multirow{4}{*}{$\begin{array}{l}\text { Laser-Base } \\
\text { Brackets }\end{array}$} & Control 1: initial SBS & 18.7460 & 5.21543 \\
\cline { 2 - 4 } & Control 2: rebond new brackets & 18.8963 & 3.14399 \\
\cline { 2 - 4 } & $30 \mu \mathrm{m}$ silanated sandblasting & 20.6750 & 3.56039 \\
\cline { 2 - 4 } & $50 \mu \mathrm{m}$ non-silanated sandblasting & 15.1088 & 2.22130 \\
\cline { 2 - 4 } & Acid Bath & 12.1700 & 1.95479 \\
\cline { 2 - 4 } & Carbide Bur & 10.2463 & 1.51222 \\
\hline
\end{tabular}

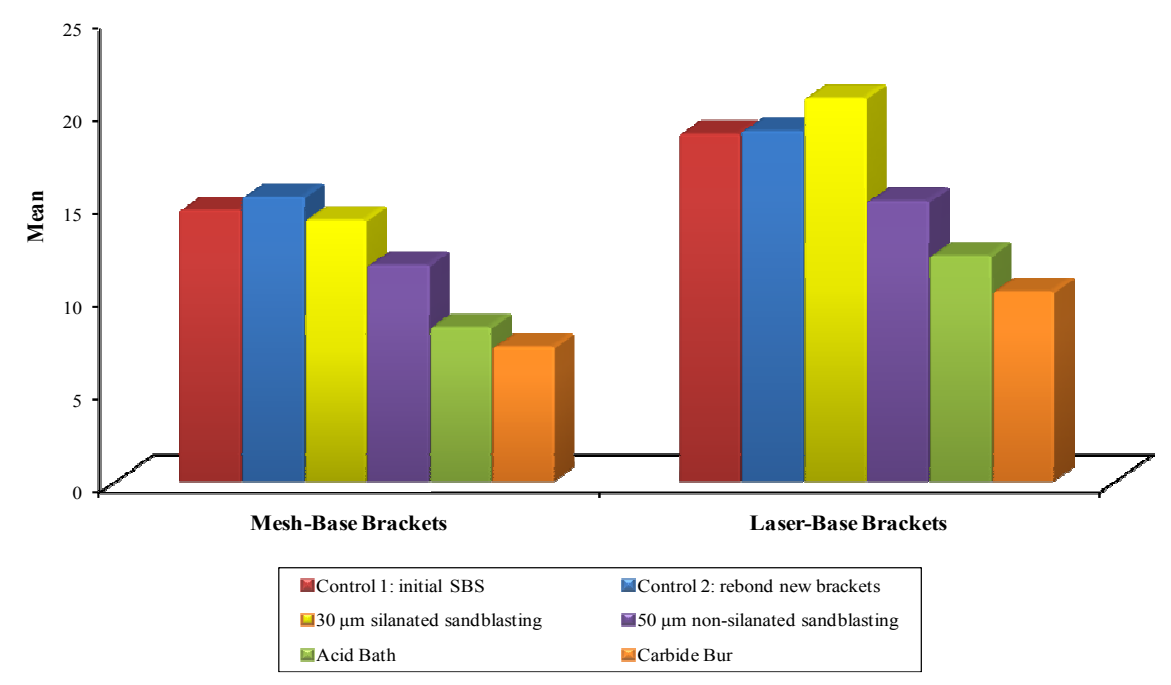

Fig. 1: Histogram showing mean shear bond strengths of the all groups and subgroups. 


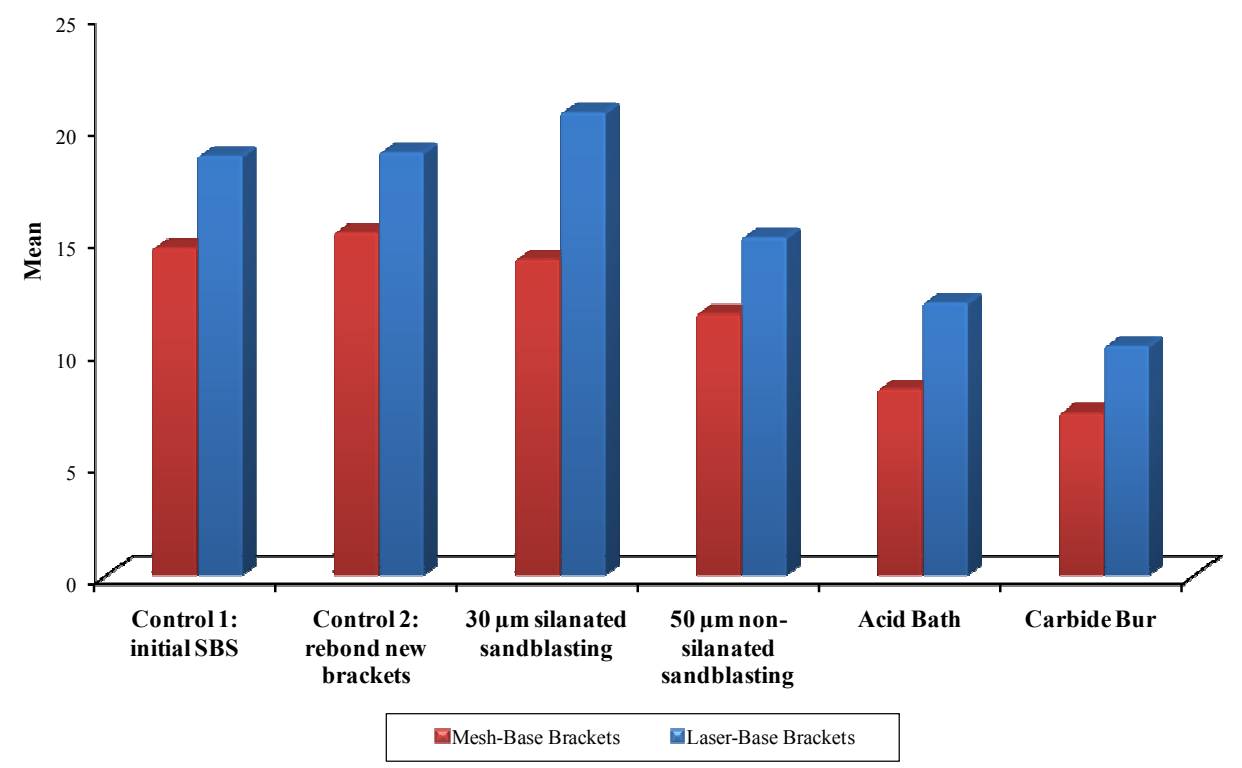

Fig. 2: Histogramshowing comparisons of meanshear bond strengths between the different groups and subgroups.

Table (V): Mean surface roughness between the different groups and subgroups.

\begin{tabular}{|c|c|c|}
\hline \multicolumn{2}{|l|}{ Samples } & $\begin{array}{c}\text { Maximum Height, } \mathbf{R}_{\mathrm{t}}(\mathrm{mm}), \\
\text { Mean Value }\end{array}$ \\
\hline \multirow{5}{*}{$\begin{array}{l}\text { Mesh-Base } \\
\text { Brackets }\end{array}$} & Debonded & 0.3071 \\
\hline & $30 \mu \mathrm{m}$ silanated sandblasting & 0.3160 \\
\hline & $50 \mu \mathrm{m}$ non-silanated sandblasting & 0.4238 \\
\hline & Acid bath & 0.3734 \\
\hline & carbide bur & 0.3076 \\
\hline \multirow{5}{*}{$\begin{array}{l}\text { Laser- } \\
\text { Structured } \\
\text { Base Brackets }\end{array}$} & Debonded & 0.1516 \\
\hline & $30 \mu \mathrm{m}$ silanated sandblasting & 0.1931 \\
\hline & $50 \mu \mathrm{m}$ non-silanated sandblasting & 0.2988 \\
\hline & Acid bath & 0.2444 \\
\hline & carbide bur & 0.0703 \\
\hline
\end{tabular}

Volume 43 - June 2013 

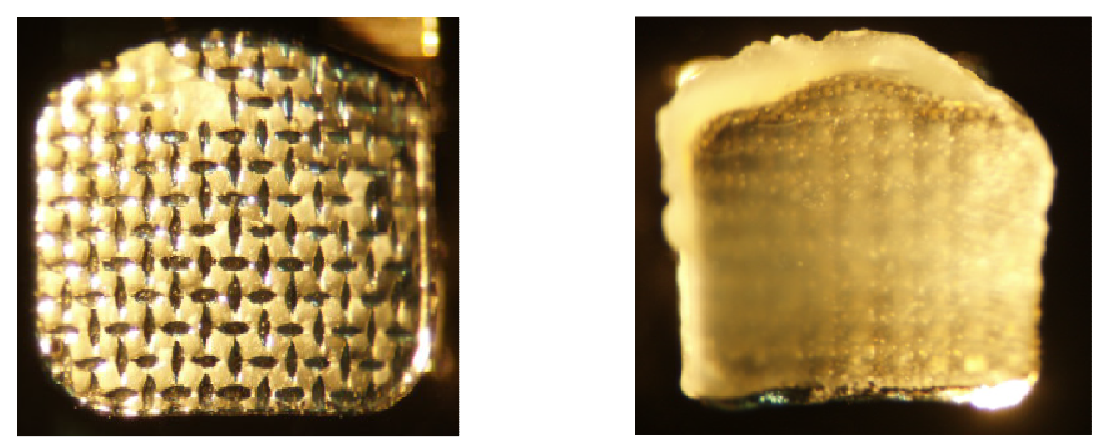

Fig. 3: Debonded brackets with adhesive on bracket base under Stereomicroscope; mesh-base bracket (left), laser-base bracket (right).

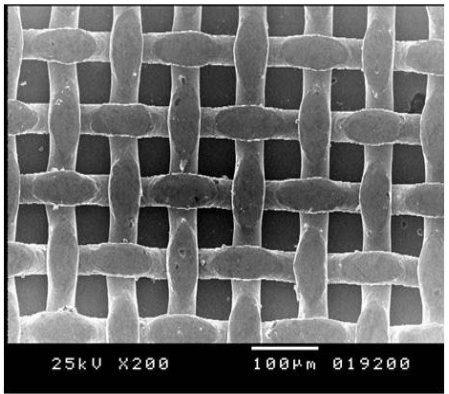

(A)

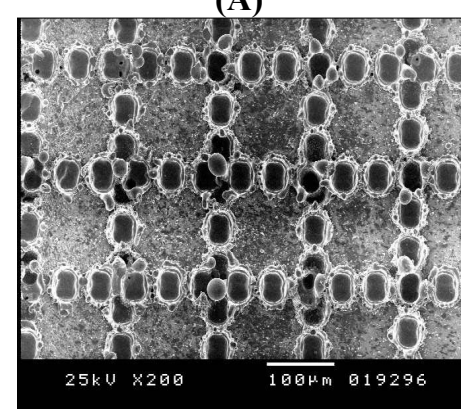

(C)

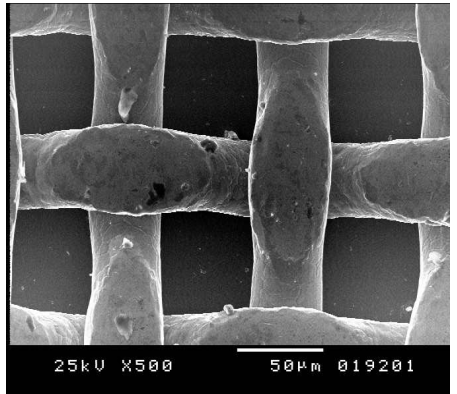

(B)

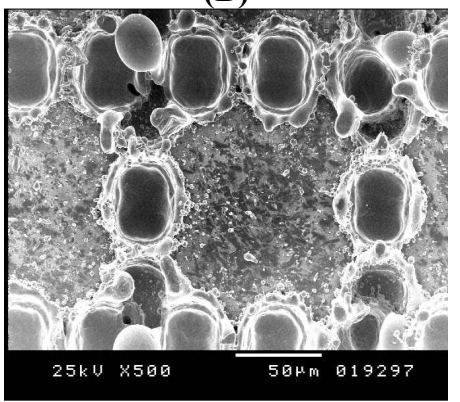

(D)

Fig. 4: Scanning electron micrographs of new brackets tested under different magnifications; (A,B) mesh-base brackets A: magnification 200, B: magnification_500. (C,D) laser-structured base brackets C: magnification_200, D: magnification_500. 


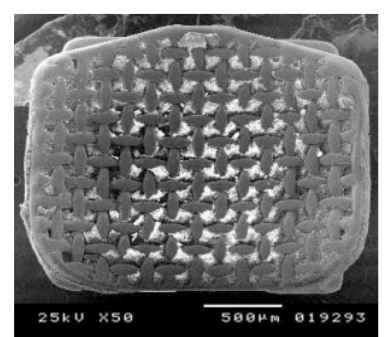

(A)

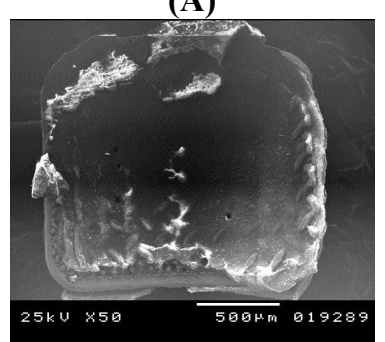

(C)

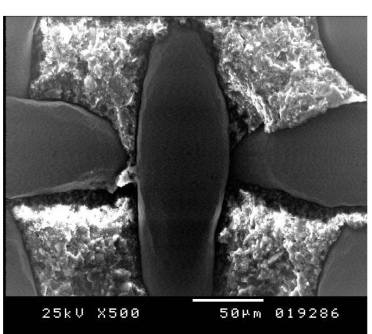

(B)

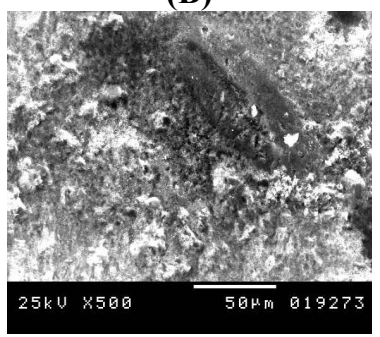

(D)

Fig. 5: Scanning electron micrographs of 2 types of brackets after debonding: (A,B) mesh-base brackets A: magnification_50, B: magnification_500. (C,D) laser-structured base bracket C: magnification_50, D: magnification_500.

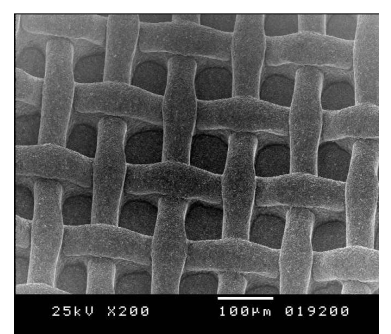

(A)

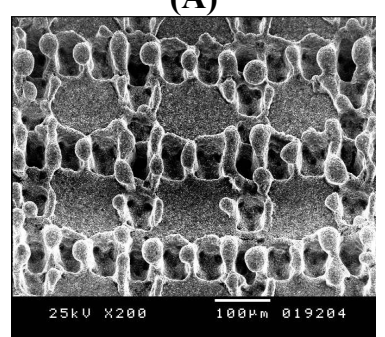

(C)

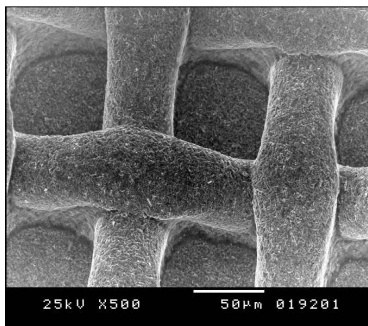

(B)

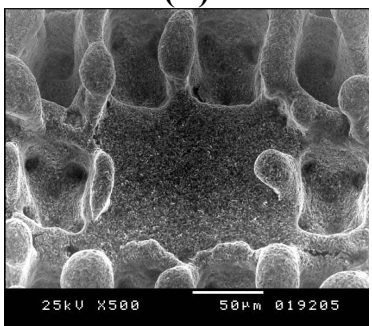

(D)

Fig. 6: Scanning electron micrographs after reconditioning with $30 \mu \mathrm{m}$ silanated aluminum oxide sandblasting particles. (A,B) mesh-base brackets A: magnification 200, B: magnification_500.(C,D) laser-structured base brackets C: magnification _ 200, D: magnification_500 


\section{Egyptian}

Orthodontic Journal

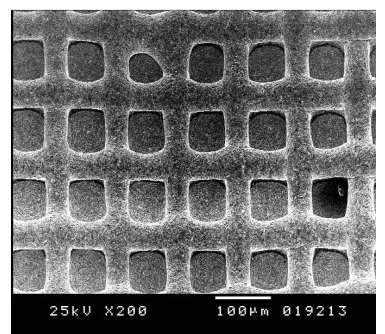

(A)

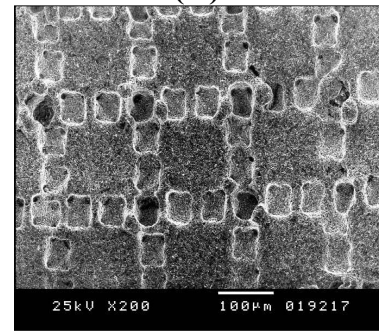

(C)

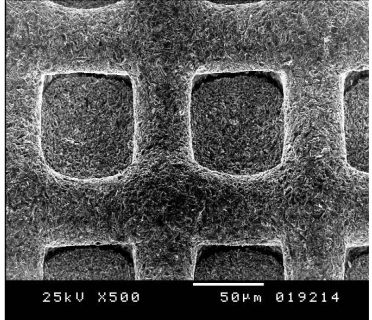

(B)

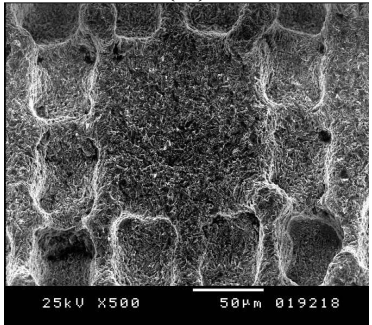

(D)

Fig. 7: Scanning electron micrographs after reconditioning with $50 \mu \mathrm{m}$ non-silanated aluminum oxide sandblasting particles.(A,B) mesh-base brackets A: magnification 200, B: magnification 500. (C,D) laser-structured base brackets C: magnification_200, D: magnification_500.

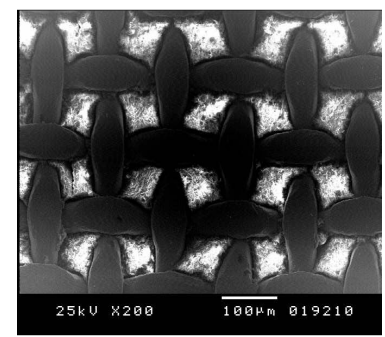

(A)

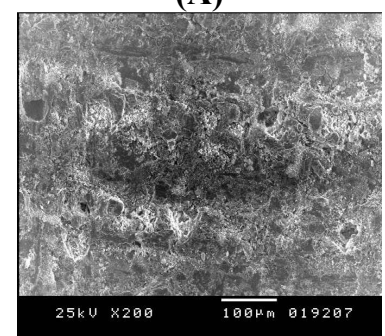

(C)

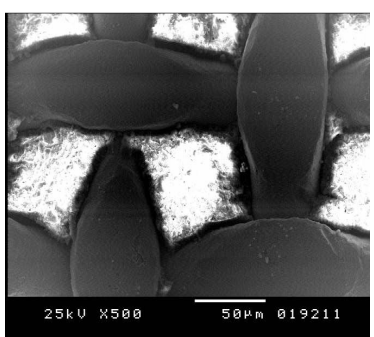

(B)

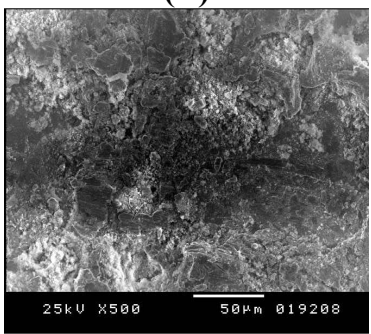

(D)

Fig. 8: Scanning electron micrographs after reconditioning with acid bath. $(\mathbf{A}, \mathbf{B})$ mesh-base brackets A: magnification 200, B: magnification 500. (C,D) laser-structured base brackets C: magnification 200, D: magnification_ $\overline{5} 00$. 


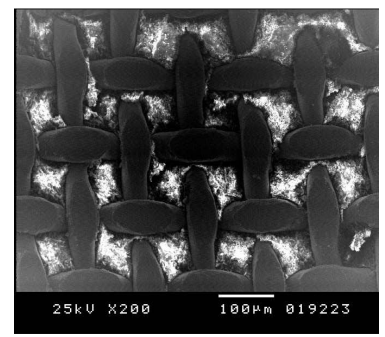

(A)

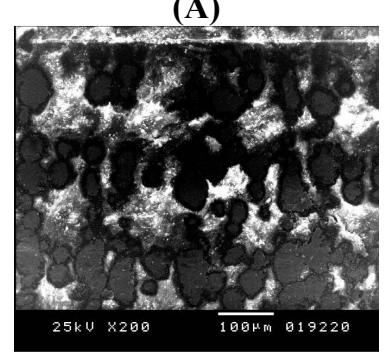

(C)

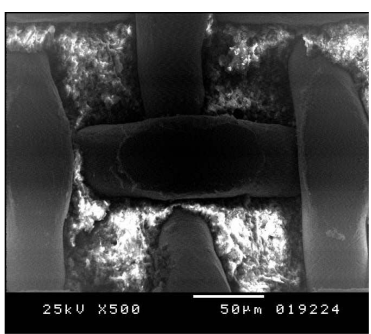

(B)

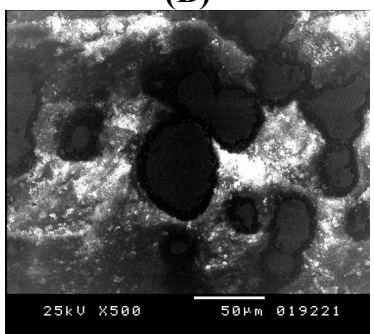

(D)

Fig. 9: Scanning electron micrographs after reconditioning with carbide bur. (A,B) mesh-base brackets A: magnification _ 200, B: magnification_500. (C,D) laser-structured base brackets C: magnification_200, D: magnification_500.

\section{DISCUSSION}

Based on the presented data, the null hypothesis was rejected. There was a difference in SBS between mesh-based and laser-structured based brackets. There was no difference in SBS between new and reconditioned brackets but there is a difference in SBS between the reconditioning techniques using sandblasting, carbide bur, and acid bath. The results of this study clearly indicated that bond strength was influenced by the retention mechanism of the laser-structured base bracket base. The laser-structured base bracket retention mechanism provided greater bond strength (mean $=18.7 \pm 5.2 \mathrm{MPa})$ when compared with the mesh-base bracket retention mechanism $($ mean $=14.6 \pm 4.2 \mathrm{MPa})$.

Reynolds $^{(12)}$ in his study has suggested 5.9 to $7.8 \mathrm{MPa}$ as the optimal bond strength required for bonding brackets to enamel. The results of this bond strength test show that laser-structured base bracket has more than 
Egyptian

Orthodontic Journal

optimal bond strength required for successful bonding. This increase in the bond strength for laser-structured base bracket may be due to the complicated microscopic and macroscopic void network developed due to laser etching provided better resin penetration and mechanical locking of orthodontic adhesive than the mesh base bracket, as shown on scanning electron microscope (SEM) (Fig. 4). Previous studies ${ }^{(13,14)}$ found that laser-structured base brackets revealed greater bond strength values when compared to mesh-base brackets which is in agreement with the current findings.

By comparing ARI scores of these two types of bracket designs, it was evident that the laser-structured base bracket had bond failure in the enamel-adhesive interface and the mesh-base bracket had bond failure in the bracket-adhesive interface. The reason for increased adhesive remaining on the laser-structured base was due to the presence of micro and macro grooves on the base, which aided in better penetration of adhesive through capillary action. This shift in the site of bond failure suggests that, there could be less iatrogenic damage caused to enamel surface after clean up procedures following debonding indicating that less chair-time would be required for removal of the adhesive ${ }^{(13)}$.

Several studies ${ }^{(15-17)}$ that assessed the effectiveness and safety of rotary instruments, advocated the use of Tungsten Carbide Burs (TCB) for the removal of the adhesive resin from the enamel surface either with adequate air cooling or suggested water spray instead of air cooling. In this work, air cooling was preferred to water cooling to assist in the observation of the resin remnants. In this study, reconditioning the enamel using a (TCB) following by acid-etching was found to produce mean shear rebond strength higher but statistically non significant from the initial shear bond strength. This was also consistent with Eminkahyagil et al. (2006) $)^{(18)}$ who studied the effect of resin removal methods on enamel surface and shear bond strength of rebounded brackets. The authors suggested that the removal of residual resin with the tungsten carbide bur then repeating the acid-etching produces some kind of roughened surface that was not present at the time of initial bonding.

Volume 43 - June 2013 
In the literature, there is no consensus on how the rebond strength compares with initial bond strength. Some authors ${ }^{(5,19,20)}$ have reported that initial bond strength is significantly greater than rebond strength. On the contrary, other studies ${ }^{(21-23)}$ reported increase in shear bond strength with chemical-cured bonding systems after rebonding. These controversies could be attributed to the types of bracket and adhesive used, reconditioning methods differences, and several laboratorial proceedings adopted. Several studies ${ }^{(1,8,24-25)}$ found that there was no significant differences between the initial and rebond shear bond strength which is consistent with this study.

In this study, no significant difference was observed in rebond bond strength when using new or reconditioned brackets. In sandblasting subgroups, the changes in the macroscopic structure caused by the debonding process and the changes in the microscopic structure caused by sandblasting of the bracket base did not detrimentally affect the rebond bond strength. This results are consistent with the results of similar studies ${ }^{(26-28)}$ who compared the in vitro shear bond strengths of previously failed metal brackets subjected to sandblasting with new untreated brackets and found no significant differences in shear bond strength between the two groups. The findings of no statistically significant differences in mean bond strength between the new brackets and brackets reconditioned by sandblasting tested in this study, supports the use of sandblasting as a viable procedure when rebonding accidentally lost brackets.

In the present study, the use of $30 \mu \mathrm{m}$ silanated particles or $50 \mu \mathrm{m}$ non-silanated particles for bracket reconditioning had similar efficacy, due to the absence of statistically significant difference between these reconditioning subgroups. Consequently, the micro-roughness created by different sized particles promoted bond strength that was not significantly different when compared to the control groups. However, $50 \mu \mathrm{m}$ non-silanated particles produced some damage to the retentive areas as shown on (SEM) (Fig.7).

Dawjee et al. (2004) ${ }^{(29)}$ described a simple, quick, and inexpensive way to clean a bracket after burning the adhesive (acid bath), and reported that a bracket that has been reconditioned with acid bath looks more like a new bracket than one that has been reconditioned using a flame and microetcher, and therefore would be more esthetically pleasing for the patient. In this 
Egyptian

Orthodontic Journal

study, the acid bath subgroups produced significantly deceased shear bond strength when compared to the control groups. This could be explained with scanning electron microscope that showed incomplete removal of adhesive from the bracket bases and the retentive areas were filled with adhesive, even though no adhesive was remaining on the bracket. Only the overhanging adhesive was found to have been removed. Moreover, carbide bur subgroups produced significantly deceased shear bond strength when compared to the control groups. These findings are similar to Kulandiavelu et al. (2009) ${ }^{(30)}$ who also found that using tungsten carbide bur produced significantly decreased bond strength than the control group, the grinding of the bracket base using tungsten carbide bur appear quick, simple and easy to perform, but the grinding leaves behind a smooth surface with much of the retentive areas being scrapped off as shown on SEM (Fig.9). This in turn leads to low bond strength values.

However, the comparisons of mean shear bond strengths of reconditioning subgroups in this study showed that, no significant difference between acid bath and carbide bur subgroups because both were not effective for complete removal of adhesive from the bracket bases. Both subgroups were not significantly different when compared to $50 \mu \mathrm{m}$ nonsilanated particles sandblast subgroup but were significantly decreased when compared to $30 \mu \mathrm{m}$ silanated particles sandblast subgroup. This indicated that $30 \mu \mathrm{m}$ silanated particles sandblast subgroup had the highest mean shear bond strength than the other reconditioning subgroups (Fig. 6).

The results of the surface roughness measurements in this study indicated that no correlation existed between bond strength and surface roughness. Previousstudies ${ }^{(31,32)}$ in the literature found that no correlation between the surface roughness and bond strength which is consistent with this study. High surface roughness measurements and low bond strength values were obtained with mesh-base brackets group compared to the laser-structured base brackets group. When considering reconditioning subgroups, the surface with the highest roughness values did not show high bond strength, and there was no correlation between the roughness created by reconditioning techniques and shear bond strength. The highest observed surface roughness measurements was caused by $50 \mu \mathrm{m}$ non-silanated sandblasting and acid bath subgroups compared with other subgroups which is in contrast to what was expected. 
Egyptian

Orthodontic Journal

\section{CONCLUSIONS}

1. Bracket reconditioning could be considered as a viable option to the clinician as there are no statistically significant differences between the mean shear bond strength and the total bond failure rate of new and reconditioned brackets.

2. Office reconditioning of stainless steel brackets by sandblasting technique showed the highest bond strength among the reconditioning techniques tested. This study confirms sandblasting as the simplest, most efficient manner of immediately reconditioning deboned brackets.

\section{REFERENCES}

1- Tavares SW, Consani S, Nouer DF, Magnani MB, Nouer PR, Martins LM. Shear bond strength of new and recycled brackets to enamel. Braz Dent J 2006; 17:44-8.

2- Owens SE, Miller BH. A comparison of shear bond strengths of three visible light-cured orthodontic adhesives. Angle Orthod 2000; 70:352-6.

3- Wang WN, Li CH, Chou TH, Wang DD, Lin LH, Lin CT. Bond strength of various bracket base designs. Am J Orthod Dentofacial Orthop 2004; 125: 65-70.

4- Smith DC, Maijer R. Improvement in bracket base design. Am J Orthod 1983; 83: 277-81

5- Knox J, Hubsch P, Jones ML, Middleton J. The influence of bracket base design on the strength of the bracket-cement interface. Br J Orthod 2000;27:249-54.

6- Bishara SE, Von Wald L, Laffoon JF, Warren JJ. The effect of repeated bonding on the shear bond strength of a composite resin orthodontic adhesive. Angle Orthod 2000; 70: 435-43.

7- Maccoll GA, Rossouw PE, Titley KC, Yamin C. The relationship between bond strength and base surface using conventional and micro-etched foil-mesh bases. Am J Orthod Dentofacial Orthop 1998; 109: 338-9. 
8- Cacciafesta V, Sfondrini MF, Melsen B, Scribante A. A 12 month clinical study of bond failures of recycled versus new stainless steel orthodontic brackets. Eur J Orthod 2004; 26: 449-54.

9- Postlethwaite K M. Recycling bands and brackets. Br J Orthod 1992; 19: 157-64.

10- Buonocore MG. A simple method of increasing the adhesion of acrylic filling materials to enamel surface. J Dent Res 1955; 34: 849-63.

11- Artun J, Bergland S. Clinical trials with crystal growth conditioning as an alternative to acid-etch enamel pretreatment. Am J Orthod 1984; 85(4): $333-40$.

12- Reynolds I R, Von Fraunhofer J A. Direct bonding of orthodontic attachments to teeth. The relation of adhesive bond strength to gauze mesh size. Br J Orthod 1976; 3: 91-95.

13- Olivier S, El Alam R, Francis C, Guy C. Comparison of bond strength between simple foil mesh and laser-structured base retention brackets. Am J Orthod Dento facial Orthop 2002; 122: 260-6.

14- Mehta O P, Saini S, Dahiya A. Comparative evaluation of shear bond strength of different bracket base designs in dry and wet environments. J IndSocPedPrev Dent2008;26(7): 104-8.

15- Retief D H, Denys F R. Finishing of enamel surface after debonding of orthodontic attachments. Angle Orthod 1979; 49: 1-10.

16- Rouleau, Marshall, Cooley. Enamel surface evaluations after clinical treatment and removal of orthodontic brackets. Am J OrthodDentofacialOrthop 1982; 81(5): 423-26.

17- Campbell P M. Enamel surfaces after orthodontic bracket debonding. Angle Orthod 1995; 65(2): 103-10.

18- Eminkahyagil N, Arman A, Cetinsahin A, Karabulut E. Effect of resin removal methods on enamel and shear bond strength of rebonded brackets. Angle Orthod 2006; 76: 314-21. 
19- Regan D, Le Masney B, van Noort R. The tensile bond strength of new and rebonded stainless steel orthodontic brackets. Eur J Orthod. 1993; $15(2): 125-35$.

20- Egan FR, Alexander SA, Cartwright GE. Bond strength of rebonded orthodontic brackets. Am J OrthodDentofacial Orthop1996;109:64-70.

21- Leas TJ, Hondrum S. The effect of rebonding on the shear bond strength of orthodontic brackets: a comparison of two clinical techniques. Am J OrthodDentofacialOrthop 1993;103:200-1.

22- Mui B, Rossouw PE, Kulkarni GV. Optimization of a procedure for rebonding dislodged orthodontic brackets. Angle Orthod 1999; 29: $276-81$.

23- Wendl B, Muchitsch P, Pichelmayer M, Droschl H, Kern W. Comparative bond strength of new and reconditioned brackets and assessment of residual adhesive by light and electron microscopy. Eur J Orthod 2011; 33: 288-92.

24- Chetan G B, Muralidhar R Y. Comparative evaluation of four office reconditioning methods for orthodontic stainless steel brackets on shear bond strength - An in vitro study. Annals and Essences of Dentistry 2011; 3(1): 6-13.

25- Farzaneh A, Mohammad B, Reza F, Mohammad M, Majid A. The Efficacy of Er, Cr: YSGG Laser in Reconditioning of Metallic Orthodontic Brackets. Photomed Laser Surg 2012; 30(1): 1-60.

26- Basudan A M, AL-Emran S E. The effects of in-office reconditioning on the morphology of slots and bases of stainless steel brackets and on the shear/peel bond strength. J Orthod 2001; 28: 231-6.

27- Andrew N. Quick, Angela M. P. Harris and Vince P. Joseph. Office reconditioning of stainless steel orthodontic attachments. European Journal of Orthodontics 2005;27:231-36.

28- Halwai HK, Kamble RH, Hazarey PV, Gautam V. Evaluation and comparision of the shear bond strength of rebonded orthodontic brackets with air abrasion, flaming, and grinding techniques: An in vitro study. Orthodontics Chic 2012 Yearbook;13(1):e1-e9. 
Egyptian

Orthodontic Journal

29- Dawjee S, Gheevarghses O. Recycling debonded brackets with an acid bath. J ClinOrthod 2004; 38:605-6.

30- Kulandaivelu T A, Ebenezar A V, Sumitha M, Dhandapani G. Comparative evaluation of the effectiveness of Er: YAG laser and other In-house refurbishing methods for reconditioning stainless steel brackets. J Oral Laser App 2009; 9: 121-27.

31- Jung M, Wehlen L O, Klimer J. Surface roughness and bond strength of enamel to composite. A Dental Materials (15) 1999; 250-56.

32- Nergiz I, Schmage P, Herrmann W, Ozcan M. Effect of alloy type and surface conditioning on roughness and bond strength of metal brackets. Am J OrthodDentofacialOrthop 2004; 125: 42-50. 